\title{
Hydrogen energy system for renewable energy consumption
}

\author{
SONG Jie ${ }^{1}$, ZHU Yuting ${ }^{1}$, LIANG Danxi ${ }^{1}$, CHENG Qing, a, YAO Dawei ${ }^{2}$ and BAO Weihan ${ }^{2}$ \\ ${ }^{1}$ Global Energy Interconnection Research Institute co., ltd, 102209, Beijing, China \\ ${ }^{2}$ Sichuan Energy Internet Research Institute, Tsinghua University, 610042, Chengdu, China
}

\begin{abstract}
As a kind of high-quality secondary energy, hydrogen has great potential of application in energy storage and utilization and contributes to consumption of renewable energy in electric power systems. To further increase the proportion of renewable energy in primary energy consumption, this article introduces a hydrogen energy system for renewable energy consumption. In this article, significance and necessity of developing hydrogen energy system are elaborated, the overall structure of hydrogen energy system is presented, key technologies involved with hydrogen system are listed, economical efficiency of hydrogen energy system is analyzed, and development of hydrogen energy system in the future is forecasted.
\end{abstract}

\section{Introduction}

In recent years, renewable energies such as wind power and photovoltaic power have increasing installed capacity, and the proportion of wind power and photovoltaic power in electric power consumption has been increasing continually ${ }^{1}$. The studies show that in 2050 , China will have up to $60 \%$ renewable energy resources and wind power and photovoltaic power generation will become foundation of electric power supply ${ }^{2}$. However, with sustained development of renewable energy, renewable energy consumption is becoming a prominent problem; China had total wind and solar energy curtailment up to 49.2 billion $\mathrm{kWh}$ in 2017; since 2018, although we have increasingly improved renewable energy consumption, we still have large volume of renewable energy curtailment, including about 21.4 billion kWh in 2019 . Renewable energy consumption has become a major factor that restricts sustainable and healthy development of renewable energies in China ${ }^{3,4}$.

The most direct solution to the issue of renewable energy consumption is to apply energy storage techniques. At present, pumped storage is a sophisticated and extensively used technique, but this energy storage scheme has special requirements for water sources and engineering application sites and is not suitable for extensive use; other energy storage techniques such as battery energy storage and compressed air energy storage are not adequate to solve of the problem of renewable energy consumption due to restrictions such as cost, efficiency and flexibility. Recently, use of renewable energy for hydrogen production and for energy storage is becoming a new trend of development. Wind and solar energy curtailment and hydrogen production can minimize energy wasting and satisfy the demand for sustainable development of green energy resources.

As a high-quality secondary energy, hydrogen has great potential of application in energy storage and utilization. Firstly, hydrogen energy is of high density and has combustion calorific value that is 3 times of that of gasoline; secondly, hydrogen energy is clean and environment-friendly and has single reaction product containing no harmful gases such as carbon monoxide, carbon dioxide and nitrogen oxides; thirdly, raw material for hydrogen is readily available, and water as reaction product of hydrogen exists in the nature and is recyclable, and hydrogen energy can be freely obtained free of resource barrier ${ }^{5}$. On this basis, study on application of hydrogen energy technology in renewable energy consumption will promote large-scale investment in construction and scientific development of renewable energy.

\section{Key technologies for hydrogen energy system}

\subsection{Hydrogen energy system structure}

The hydrogen energy system for new energy consumption is an autonomously running energy system composed of renewable energy power generation equipment (photovoltaic, wind power, etc.), energy conversion equipment, energy storage equipment (electricity and gas storage), energy consuming equipment and other elements and can be structurally divided into sections such as energy input, conversion, storage and output. Typical hydrogen energy system structure is as shown on Fig. 1:

\footnotetext{
${ }^{\mathrm{a}}$ Corresponding author: chengqing@tsinghua-eiri.org
} 


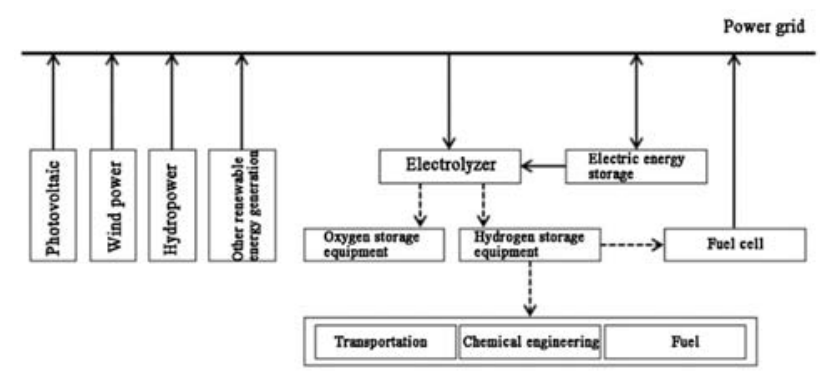

Fig. 1. Diagram of Hydrogen Energy System Structure

On Fig. 1, solid lines stand for electric energy transmission and dashed lines stand for gas transmission. When electric power generated using renewable energy cannot be accommodated by power grid, electrolyzer can be used for hydrogen production using surplus electric power, and hydrogen energy can be stored or supplied to hydrogen consumers. When electric power generated using renewable energy is insufficient, fuel cell can use stored hydrogen for generating power to make up for deficiency of power generation. The electric energy storage equipment in the system can be directly used for electric energy storage and can also be used as the power source for hydrogen production through electrolysis.

\subsection{Electricity-hydrogen conversion technology}

\subsubsection{Renewable energy generation}

Wind energy and solar energy are the most representative ones in renewable energy generation. Compared with traditional fossil energies, they are widely distributed and inexhaustible. With increase of installed capacity of intermittent renewable energy generation equipment such as wind and photovoltaic power generation equipment, high uncertainty of renewable energy output and problems resulted from electric power electronization such as low inertia, poor immunity and multi-time scale response will give rise to great challenge in electric power subsystem operation and control. To have high proportion of renewable energy consumption in hydrogen energy system, renewable energy forecasting techniques must be improved, and study on stability analysis theory and optimal operation method with respect to system related problems is to be carried out ${ }^{6}$.

\subsubsection{Hydrogen production technology}

Hydrogen production is the basis of the whole hydrogen energy system. According to classification of energy resources for hydrogen production, hydrogen production technologies include hydrogen production through reforming, hydrogen as industrial byproduct, hydrogen production using chemical materials and the cutting-edge hydrogen production technologies (hydrogen production using biomass, water electrolysis for hydrogen production, water pyrolysis for hydrogen production, etc.), and water electrolysis for hydrogen production is one of the important way of renewable energy consumption.
Water electrolysis for hydrogen production is a sophisticated technique and has simple process flow, and there is no harmful gas emission during hydrogen production; hydrogen production equipment is quick in startup and response and has wide range of operating load and can easily adapt to and match the undulatory property of renewable power. However, as water electrolysis for hydrogen production has high power consumption and 5 $\mathrm{kWh}$ electric energy is required for making a standard cubic feet hydrogen, hydrogen production is costly, it is not extensively used. Hydrogen production using renewable energies such as "wind and photovoltaic energies curtailment" can effectively promote utilization of renewable energy and reduce cost of hydrogen production $^{7}$.

Table 1 shows comparison of main performances of the three techniques of hydrogen production through electrolysis: alkaline electrolysis, SOEC electrolysis and PEM electrolysis 8 .

Table 1. Comparison of Techniques of Water Electrolysis for Hydrogen Production

\begin{tabular}{|c|c|c|c|}
\hline & $\begin{array}{c}\text { Operating } \\
\text { temperature } \\
{ }^{\circ} \mathrm{C}\end{array}$ & $\begin{array}{c}\text { Working } \\
\text { zone } \\
\%\end{array}$ & $\begin{array}{c}\text { System } \\
\text { efficiency } \\
\%\end{array}$ \\
\hline alkaline & $60-90$ & $10-110$ & $62-70$ \\
\hline SOEC & $600-1000$ & $20-100$ & $74-81$ \\
\hline PEM & $50-80$ & $0-160$ & $56-60$ \\
\hline
\end{tabular}

Alkaline electrolysis and PEM electrolysis are lowtemperature electrolysis techniques and have $50-90^{\circ} \mathrm{C}$ operating temperature and single reactor power up to $\mathrm{MW}$ grade and have been put into industrial use and have system efficiency up to $70 \%$. SOEC electrolysis emerging in recent years is a high-temperature electrolysis technology and has $600-1000^{\circ} \mathrm{C}$ operating temperature and higher conversion efficiency as compared with the aforesaid techniques.

\subsubsection{Fuel cell technology}

Fuel cells and electrolytic cells have similar physical structure which is composed of cathode, anode and electrolyte. The working process is almost the reverse process of electrolysis for hydrogen production, during which, oxides and fuels are introduced into the cathode and anode where combination reaction occurs and electric energy is generated.

Fuel cells includes AFC (alkaline fuel cell), PAFC (phosphoric acid fuel cell), SOFC (solid oxide fuel cell), MCFC (molten carbonate fuel cell) and PEMFC (proton exchange membrane fuel cell) 9 .

As intermittent renewable energies have intermittent and random output, fuel cells used in hydrogen energy system must be capable of fast conversion of electric energy output power according to real-time system status, and the control system usually regulates output electric power of fuel cells by regulating intake flow into fuel cells. 


\subsection{Hydrogen energy storage technology}

Hydrogen storage is the key and bottleneck in application of hydrogen energy system. As hydrogen has low density and extremely low liquefaction temperature (critical liquefaction temperature is $-239.9^{\circ} \mathrm{C}$, and liquefaction temperature is as low as $-252.77^{\circ} \mathrm{C}$ at standard atmospheric pressure), storage of hydrogen at high density is a difficult problem, and application of hydrogen energy is restricted.

Hydrogen storage can be classified into three categories on status basis, namely, liquid hydrogen storage at low temperature, gaseous hydrogen storage at high pressure and solid adsorption storage. Main parameters of the hydrogen storage technologies are shown in Table 211. As liquid hydrogen storage is costly, it is mainly used in aerospace industry as rocket propellant. In civil applications, cheap high-pressure hydrogen storage technology is used. As hydrogen has low boiling point by nature, hydrogen liquefaction is hard to go down a lot with development of technologies, hydrogen storage at solid state that has high volume energy density would have a promising prospect. With development and popularization of technologies, cost of hydrogen storage is expected to have a sharp fall, and in the future, such technology is expected to substitute high-pressure hydrogen storage that is at the dominant position at present. However, hydrogen storage at high pressure will still be the preferred hydrogen storage technology for hydrogen energy system.

Table 2. Comparison Among Hydrogen Storage Technologies

\begin{tabular}{|c|c|c|c|c|}
\hline \multicolumn{2}{|c|}{$\begin{array}{l}\text { Hydrogen storage } \\
\text { method }\end{array}$} & $\begin{array}{c}\text { Specific } \\
\text { volume } \\
\mathrm{L} / \mathrm{kg}\end{array}$ & $\begin{array}{c}\text { Efficiency } \\
\%\end{array}$ & $\begin{array}{c}\text { Leakage } \\
\text { ratio } \\
\% / \text { day }\end{array}$ \\
\hline \multirow{2}{*}{$\begin{array}{l}\text { Gaseou } \\
\text { s state }\end{array}$} & $30 \mathrm{Mp}$ & 40 & 91 & $\begin{array}{c}0.00002 \\
4\end{array}$ \\
\hline & $70 \mathrm{Mp}$ & 28 & 90 & 0.00033 \\
\hline \multicolumn{2}{|c|}{ Liquid state } & 14 & $62-77$ & 1 \\
\hline \multicolumn{2}{|c|}{$\begin{array}{l}\text { Activated carbon } \\
\text { adsorption }\end{array}$} & 25 & $91-93$ & 0.2 \\
\hline \multirow{2}{*}{$\begin{array}{c}\text { Metal } \\
\text { Hydride }\end{array}$} & $\begin{array}{c}\text { Low } \\
\text { temperature } \\
<100^{\circ} \mathrm{C}\end{array}$ & 9 & $90-93$ & - \\
\hline & $\begin{array}{c}\text { High } \\
\text { temperature } \\
>300^{\circ} \mathrm{C} \\
\end{array}$ & 10 & $79-83$ & - \\
\hline
\end{tabular}

\subsection{Hydrogen energy transmission technology}

At present, hydrogen energy is mainly transmitted with compressed gas truck, low-temperature liquid hydrogen truck and through pipelines, as shown in Table $3{ }^{12}$.

Table 3. Comparison among Hydrogen Transmission Technologies.

\begin{tabular}{|l|l|c|c|}
\hline & & $\begin{array}{c}\text { Low- } \\
\text { temperatu } \\
\text { re liquid } \\
\text { hydrogen } \\
\text { Truck }\end{array}$ & $\begin{array}{c}\text { Compresse } \\
\text { d gaseous } \\
\text { hydrogen } \\
\text { Truck }\end{array}$ \\
\hline
\end{tabular}

\begin{tabular}{|c|c|c|c|}
\hline $\begin{array}{c}\text { Transmission } \\
\text { capacity }\end{array}$ & $100 \mathrm{t} / \mathrm{h}$ & $\begin{array}{c}4 \\
\mathrm{t} / \mathrm{vehicle}\end{array}$ & $\begin{array}{c}0.4 \\
\mathrm{t} / \mathrm{vehicle}\end{array}$ \\
\hline $\begin{array}{c}\text { Transmission } \\
\text { distance }\end{array}$ & Long & Long & Short \\
\hline $\begin{array}{c}\text { Energy for } \\
\text { transmission }\end{array}$ & Compressor & $\begin{array}{c}\text { Transport } \\
\text { fuel }\end{array}$ & $\begin{array}{c}\text { Transport } \\
\text { fuel }\end{array}$ \\
\hline Efficiency & $\begin{array}{c}99 \% / 100 \\
\mathrm{~km}\end{array}$ & $\begin{array}{c}99 \% / 100 \\
\mathrm{~km}\end{array}$ & $\begin{array}{c}94 \% / 100 \\
\mathrm{~km}\end{array}$ \\
\hline
\end{tabular}

Hydrogen transmission method is to be selected considering hydrogen production site, traffic conditions, freight volume, transportation distance and market price. At present, hydrogen for large-sized hydrogen users is usually transmitted through pipeline network, and hydrogen for scattered hydrogen users that are not far away is transported with carriers such as tube trailers. Moreover, tube trailer transport technology is very sophisticated, and transportation cost will not drop significantly in the future but will be subject to oil price fluctuation; hydrogen transmission pipeline technology is still to be improved; experiences in natural gas construction are used for reference in hydrogen transmission pipeline construction at present, and experience in hydrogen piping construction is deficient; but hydrogen transmission pipeline has transmission stability and transmission volume regulation capability incomparable by tube trailer, and what the control system needs to do is just effectively adjusting rate of hydrogen delivery to hydrogen users.

In the long run, hydrogen transmission network composed of hydrogen transmission pipelines is more suitable for application in hydrogen energy system for renewable energy consumption. To reduce hydrogen transmission pipeline construction cost, electrolysis equipment for hydrogen production, hydrogen storage equipment and fuel cells can be provided nearby hydrogen users in so far as possible so that hydrogen transmission distance can be shortened.

\subsection{Hydrogen energy application technology}

Application of hydrogen energy is the key link of renewable energy consumption, and hydrogen is mainly for two applications at present: it is used as a feed gas in traditional industries or chemical industries and as a secondary energy in transportation, energy and other emerging industries. Main applications of hydrogen are shown on Fig. 2: 


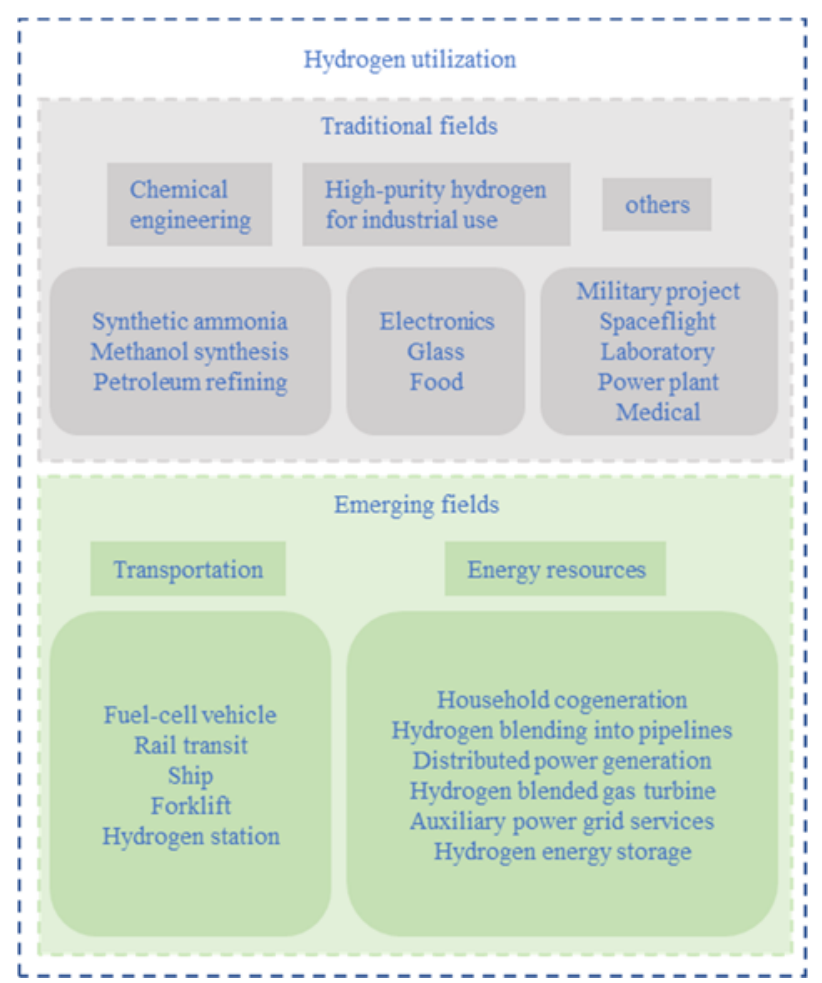

Fig. 2. Main Application Fields of Hydrogen Energy

In traditional fields of hydrogen use, hydrogen as an important petrochemical material or raw gas for producing synthetic ammonia and methanol accounted for more than $70 \%$ of industrial use of hydrogen at present 13 . And hydrogen is also used as protective gas, reducing gas and reaction gas in electronic industry, metallurgical industry, food industry, float glass, fine organic synthesis, aerospace industry and other fields.

Hydrogen is not only widely used as a chemical material in traditional applications, but also can be used as a clean and efficient secondary energy in fuel cells and stationary power stations, and it can be injected into natural gas pipelines for transportation, civil use and industrial use. With respect to renewable energy consumption, application of hydrogen energy is considered as a new way of hydrogen energy application based on the advanced water electrolysis technology, hydrogen storage technology and fuel cell technology.

\section{Economic Efficiency Analysis of Hydrogen Energy System}

\subsection{Construction cost}

Construction cost is a one-off investment before a hydrogen energy system is put into operation, including cost of water electrolysis equipment for hydrogen production, hydrogen storage equipment and fuel cell. At present, hydrogen energy system construction is still costly. With expansion of related manufacturing industry, cost of terminal equipment is expected to drop significantly.

1. Electrolyzer cost
Table 1 provides three categories of water electrolysis for hydrogen production, and cost of alkaline electrolyzer is USD $400-600 / \mathrm{kW}$, cost of solid oxide electrolyzer is USD $1000-1500 / \mathrm{kW}$ and cost of proton exchange membrane electrolyzer is about USD $2000 / \mathrm{kW} 14$. If unit construction cost of electrolyzer is $\mathrm{C} 1$ and size is Ps, construction cost $\mathrm{Cd}$ of electrolyzer is:

$$
C_{\mathrm{d}}=C_{1} * P_{\mathrm{s}}
$$

\section{Cost of hydrogen storage equipment}

The hydrogen energy system for accommodating renewable energies applies hydrogen storage at high pressure, and construction cost equation is given below:

$$
C_{\mathrm{c}}=C_{\mathrm{p}} * P_{\mathrm{nax}}+C_{\mathrm{r}} * Q_{\max }
$$

Where Pnax is the maximum output power of energy storage system, $\mathrm{Cp}$ is unit power cost of energy storage system, Qmax is the maximum energy storage capacity of energy storage system, and $\mathrm{Cr}$ is unit capacity cost of energy storage system. If above-ground hydrogen storage tank is used for storing hydrogen, construction cost is relatively high. If only cost of hydrogen storage tank is considered, unit capacity cost $\mathrm{Cr}$ is about USD $15 / \mathrm{kWh} 15$, which together with land cost and infrastructure construction costs, gives rise to cost higher than $\mathrm{Cr}$. There are no data about unit power cost. However, if there are cave cavities and used wells available for storing hydrogen underground at pressure, construction cost of the hydrogen storage system is relatively low. According to the data in references 15 and 16, unit power cost Cp of underground hydrogen storage system is about USD 140 $/ \mathrm{kW}$, and unit capacity cost $\mathrm{Cr}$ can be as low as USD 0.3 $/ \mathrm{kWh}$.

\section{Fuel cell cost}

Unit cost of fuel cell is about USD $1,500 / \mathrm{kW} 17$. In the future, with increase of capacity of single fuel cell system and popularization of fuel cell application, there will be great reduction of unit cost of fuel cell. United States Department of Energy has set a medium-term target of USD $700 / \mathrm{kW}$ and a long-term target of USD $434 / \mathrm{kW}$. Assuming that unit construction cost of a fuel cell system is $\mathrm{C} 2$ and system capacity is $\mathrm{Pl}$, an equation for calculating construction cost $\mathrm{Cd}$ of a fuel cell system is available:

$$
C_{\mathrm{d}}=C_{2} * P_{1}
$$

4. Transmission equipment cost

Different transmission methods have significant difference in cost. Cost of pipeline transmission is about USD $0.1-1.0 / \mathrm{kg} / 100 \mathrm{~km}$, cost of transport using lowtemperature liquid hydrogen truck is USD $0.3-0.5$ $/ \mathrm{kg} / 100 \mathrm{~km}$, and cost of transport using compressed air truck is up to USD $0.5-2.0 / \mathrm{kg} / 100 \mathrm{~km}$.

\subsection{Running cost}

During operation of the hydrogen energy system, to maintain normal operation of the system, expenses are to be spent continuously. For general industrial projects, expenses of raw material purchasing and replenishing often account for the vast majority of operating expenses. 
Electricity cost in the hydrogen energy system elaborated in this article accounts for the largest proportion, but the system is designed for producing hydrogen for "curtailment of wind and photovoltaic energies ". In operating period, theoretical electricity expense is 0 , and operating expenses are mainly spent on management, maintenance and hydrogen energy transmission. Project management and maintenance cost is usually estimated considering the ratio between average management and maintenance expenditure in each year during the operation of the system and total construction investment at the initial stage of a project. As management and maintenance of subsystems of the hydrogen energy system have different focus, independent accounting is required. Accounting proportion is shown in Table $4^{18}$ :

Table 4. Management \& Maintenance Cost

\begin{tabular}{|c|c|c|c|}
\hline & Electrolyzer & $\begin{array}{c}\text { Hydrogen } \\
\text { storage }\end{array}$ & Fuel cell \\
\hline Proportion & $4 \%$ & $1 \%$ & $4 \%$ \\
\hline
\end{tabular}

In addition, different hydrogen energy transmission modes have significantly different costs. Cost of pipeline transmission is about USD $0.1-1.0 / \mathrm{kg} / 100 \mathrm{~km}$, cost of transport with low-temperature liquid hydrogen truck is USD $0.3-0.5 / \mathrm{kg} / 100 \mathrm{~km}$, and cost of transport with compressed air truck is USD $0.5-2.0 / \mathrm{kg} / 100 \mathrm{~km}$.

\section{Development and application prospect}

The hydrogen energy system referred to in this article is a new energy system which accommodates a large proportion of renewable energy. Up to now, research on key technologies of hydrogen energy system has achieved initial success, and introduction of policies has laid a solid foundation for further development of hydrogen energy system, and breakthrough can be made in the following aspects in the future:

1. Strengthen technology research and development and achieve optimal cost. Although hydrogen energy system has significant advantages in renewable energy utilization, development at present is restricted by high technological cost, and efforts are still to be made to find a way to optimal cost. Study on hydrogen energy storage system development in the future must be in combination with chemistry, biology, material science and other disciplines so that breakthrough in key techniques such as high-efficiency hydrogen production, low-cost hydrogen storage and high-efficiency discharge can be made; route of reduction of cost of hydrogen production and storage and supporting facilities is to be studied, and efficiency of system utilization is to be improved to reduce unit cost and improve economic benefits.

2. Improve supporting facilities and optimize comprehensive benefits. As supporting facilities and industry chain for hydrogen energy system utilization are incomplete and efficiency of comprehensive utilization is still to be improved, improvement can be made in the future through cooperation with government departments. With support of government policies, to accelerate construction of experimental units for hydrogen energy system and to study direction of development of hydrogen-powered vehicles market; to consider development of multi-channel energy utilization such as gas-heat cogeneration, to improve comprehensive utilization of hydrogen energy system; to build a benefit evaluation system for hydrogen energy system projects for providing quantitative evaluation of demonstration projects and improve comprehensive benefits.

3. Uplift application level and expand utilization. In a situation that application mode of combining hydrogen energy with distributed energy is not sophisticated, study on hydrogen energy system capacity configuration can be considered in the future to allow consumption of renewable energy; the energy resources are to be coupled and a complementary wind and photovoltaic power generation for storing energy is to be developed; study on combination with hydrogen energy system is to be carried out in the case of micro-grid and disconnection from the grid to allow power supply for remote districts; study on offshore combined wind-hydrogen energy system can be carried out to promote expansion of application.

4. Optimize control strategy and increase economic benefits. Hydrogen energy storage in energy internet can not only decouple the relationship between electric energy production and consumption as traditional energy storage technology does, but also convert electric energy into hydrogen energy which flows among different energy networks and end users. Study on coordinated control model of hydrogen-bearing energy internet and optimized control strategy is conducive to full utilization of advantages of the complementary multiple energy resources in the energy internet, improving comprehensive energy utilization and improving economic benefits of the Energy Internet.

\section{Acknowledgement}

Project name: Research on development path and key technology of energy storage in future power grid
Project number:
2018-2020SGGR0000DLJS1801307

\section{References}

1. LIU Zhenya. Global energy interconnection [M]. Beijing: China Electric Power Press, 2015.

2. WANG Chengliang, LIU Hong, GONG Jianfeng, et al. Joint scheduling of different energy storage for improving wind power consumption ability in integrated community energy system $[\mathrm{J}]$.Electric Power Construction, 2018, 39(4): 35-44.

3. SHU Yinbiao, ZHANG Zhigang, GUO Jianbo, et al. Study on Key Factors and Solution of Renewable Energy Consumption[J], Proceedings of the CSEE, 2017, 37(1): 1-9.

4. Yang Jingwei, ZHANG Ning, WANG Yi, et al. Multi-energy System Towards Renewable Energy Consumption: Review and Prospect[J]. Automation of Electric Power Systems. 2018, 42(4): 11-24. 
5. Chi Jun,Yu Hongmei. Water electrolysis based on renewable energy for hydrogen production[J]. Science Direct,2018,39 (3): 390-394.

6. KANG Chongqing, YAO Liangzhong. Key Scientific issues and theoretical research framework for power systems with high proportion of renewable energy [J]. Automation of Electric Power Systems, 2017, 41 (9): 1-11.

7. Hao Weifeng, Jia Danyao, Li Hongjun. Overview of water electrolysis technology for hydrogen production based on renewable energy [J]. Value Engineering, 2018,37 (29): 236-237.

8. Cheng Jun, Ye Fang, Zhang Wei, et al. Situation of Development of Proton Exchange Membrane Electrolyzers for Energy Storage. Chemistry and Biomedical Engineering, 2015(1): 1 7.

9. Cai Guowei, Kong Lingguo, Xue Yu, et al. Overview of Wind-hydrogen Coupling Power Generation Technology. Power System Automation, 2014(21): $127 \sim 135$.

10. XU Li, MA Guang, SHENG Peng, et al. Overview of hydrogen storage technologies and their application prospects in hydrogen-based energy storage [J]. Smart Grid, 2016, 4 (2): 166-171.

11. Xu Wei, Tao Zhanliang, Chen Jun. Progress of Research on Hydrogen Storage. Progress in Chemistry, 18(2): 200 210.

12. ZHAO Y, GONG M, ZHOU Y, et al. Thermodynamics analysis of hydrogen storage based on compressed gaseous hydrogen, liquid hydrogen and cryo-compressed hydrogen [J]. International Journal of Hydrogen Energy, 2019, 44 (31): 1683316840.

13. Huo Xianxu, Wang Jing, Jiang Ling, et al. Overview of Key Technologies and Applications of Hydrogen Energy Storage System [J]. Energy Storage Science and Technology, 2016: 197-203.

14. Cheng Jun, Ye Fang, Zhang Wei, et al. Situation of Development of Proton Exchange Membrane Electrolyzers for Energy Storage. Chemistry and Biomedical Engineering, 2015(1): 1 7.

15. Schoenung Susan. Economic Analysis of Bulk Hydrogen Storage for Renewable Utility Applications. 2011.

16. Ludwig M, Haberstroh C, Hesse U. Exergy and cost analyses of hydrogen-based energy storage pathways for residual load management. International Journal of Hydrogen Energy, 2015, 3(35): 11348 11355.

17. Carmo M, Fritz D L, Mergel J, et al. A comprehensive review on PEM water electrolysis. International Journal of Hydrogen Energy, 2013, 38(12): 4901 4934.

18. Beccali M, Brunone S, Finocchiaro P, et al. Method for size optimisation of large wind- hydrogen systems with high penetration on power grids. Applied Energy, 2013, 102(2): 534 544. 